\title{
Цифровая трансформация радиоэлектроники
}

\author{
А. Фомина, д. э. н. ${ }^{1}$
}

УДК 311.42 | ВАК 05.27 .06

\begin{abstract}
Распоряжением Правительства РФ № 1632-р от 28 июля 2017 года была утверждена программа “Цифровая экономика Российской Федерации", призванная активизировать и свести в единую систему процессы цифровой трансформации в нашей стране, в 2018 году она была преобразована в национальную программу со значительными корректировками входящих в ее состав планов мероприятий, но с сохранением первоначального срока реализации - до 2024 года. На сегодняшний день главными достигнутыми в этом направлении результатами стали формирование понятийной базы, вовлечение в процесс цифровизации большинства крупных игроков рынка, а также подготовка части методологической и нормативной базы, необходимой для интенсификации развития страны в целом. В статье представлены результаты исследования "Цифровая трансформация радиоэлектроники", являющегося попыткой подведения первых итогов формирования цифровой экономики в сфере радиоэлектроники.
\end{abstract}

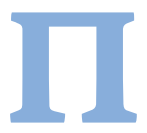

о результатам проведенного исследования, ряд технологий «Индустрии 4.0» активно внедряется и применяется в российской радиоэлектронной промышленности. Наибольший интерес для организаций российской радиоэлектронной промышленности представляют технологии 3D-печати, которые используются при создании макетов и прототипов, в опытном и реальном производстве, развитии материально-технической базы. Организации радиоэлектронной промышленности в своей деятельности применяют технологии больших данных, Интернета вещей, печатной электроники, суперкомпьютерных, квантовых и параллельных вычислений, искусственного интеллекта и готовы развивать эти направления в дальнейшем. Такие технологии, как виртуальная и дополненная реальность, распределенный реестр и блокчейн, автономные роботы на данный момент не используются в организациях, принявших участие в исследовании.

Несмотря на то, что цифровые технологии открывают предприятиям новые возможности, связанные с повышением эффективности и расширением сферы деятельности, организации российской радиоэлектронной промышленности осваивают их не столь быстро, какхотелось бы. В то же время, согласно данным проведенного опроса, организации российской радиоэлектронной промышленности демонстрируют готовность участвовать в цифровой трансформации, в том числе работая над созданием

ЦнИи «Электроника», генеральный директор. собственных цифровых продуктов, услуг и технологий по самому широкому кругу направлений.

На данный момент в организациях российской радиоэлектронной промышленности наиболее автоматизированы процессы, не являющиеся специфическими для отрасли и широко применяющиеся в различных компаниях вне зависимости от их профиля. Речь идет о бухгалтерском учете, уровень автоматизации которого практически достиг 100\%, а также складских процессах и документообороте, уровень автоматизации которых превышает 50\%. К сожалению, доля автоматизации бизнес-процессов, отражающих отраслевые особенности, существенно ниже. Так, сфера управления производством автоматизирована лишь на треть.

В краткосрочных планах организаций не только дальнейшее развитие систем автоматизации складских процессов и документооборота, но и увеличение уровня автоматизации по таким направлениям, как управленческий учет, управление производством, управление взаимоотношениями с поставщиками (SRM) и клиентами (CRM).

Если для автоматизации универсальных для различных сфер экономики процессов организации радиоэлектронной промышленности применяют готовые решения, в том числе популярную на российском рынке линейку продукции 1С, то среди систем управления производством, обладающим определенными отраслевыми особенностями, высока доля собственных разработок. 


\section{ОБ ИССЛЕДОВАНИИ}

Исследование было инициировано ЦНИИ «Электроника». Партнерами проекта выступили ведущий отраслевой научно-технический журнал «ЭЛЕКТРОНИКА: Наука, Технология, Бизнес" и АНО “Цифровая экономика».

Цель исследования - анализ процессов цифровой трансформации радиоэлектронной промышленности, выявление существующих трендов, стимулов и барьеров, оценка планов организаций в области цифровой трансформации в ближайшей перспективе.

В ходе исследования были опрошены руководители организаций радиоэлектронного комплекса различного масштаба - от небольших компаний до крупнейших концернов и холдингов. К анализу полученных данных и выявленных закономерностей были привлечены эксперты ведущих отраслевых организаций.

Основную долю организаций, принявших участие в опросе, представляют производственные (47\%) и научно-производственные (40\%) организации, при этом 45\% респондентов являются представителями крупного бизнеса, 31\% - среднего бизнеса, 24\% - малого и микробизнеса, что отражает особенности российской радиоэлектронной промышленности с ее склонностью к концентрации ресурсов [2].

\section{ТЕХНОЛОГИИ "ИНДУСТРИИ 4.0»}

Наибольшим потенциалом развития среди технологий «Индустрии 4.0» для организаций радиоэлектронной промышленности отличаются технологии 3D-печати: 48\% респондентов отмечают применимость данной технологии, при этом у 18\% она уже внедрена, 20\% планируют внедрение (рис. 1). 3D-печать используется при создании макетов, прототипов и опытных образцов (например, в сфере микроэлектроники), производстве деталей (например, антенных элементов), изготовлении оснастки для станков с чПУ. В планах организаций - использование 3D-печати при изготовлении СВЧ-электроники и производстве магнитотвердых материалов. Кроме того, 3D-печать применима при создании производственных креплений, вспомогательного оборудования для производства электронной компонентной базы, при моделировании продукции.

На данный момент в организациях радиоэлектронной промышленности не внедрены технологии виртуальной и дополненной реальности, распределенного реестра и блокчейн, автономные роботы. При этом 7\% респондентов отметили, что в краткосрочной перспективе планируют использовать технологии виртуальной и дополненной реальности в системах документооборота, для обеспечения процессов обучения персонала, пользователей, партнеров и заказчиков, виртуальной пуско-наладки, технического обслуживания и ремонта оборудования. Технологии виртуальной и дополненной реальности могут сочетаться с геопространственными технологиями и в конечном итоге быть использованы для реализации концепции интеллектуального производства (Smart Factory).

Технологии распределенного реестра и блокчейн в краткосрочной перспективе предполагают использовать 3\% опрошенных организаций в системах обработки информации и при развитии смарт-контрактов. Если говорить об общем потенциале развития данного направления в радиоэлектронной промышленности, то, по мнению респондентов, в перспективе технологии распределенного реестра и блокчейн могут быть использованы при внедрении CALS-технологий, связанных с информационной поддержкой на всех этапах жизненного цикла изделия, при создании баз данных производимой и применяемой ЭКБ отечественного и иностранного производства, для налаживания работы с внешними организациями (например, при

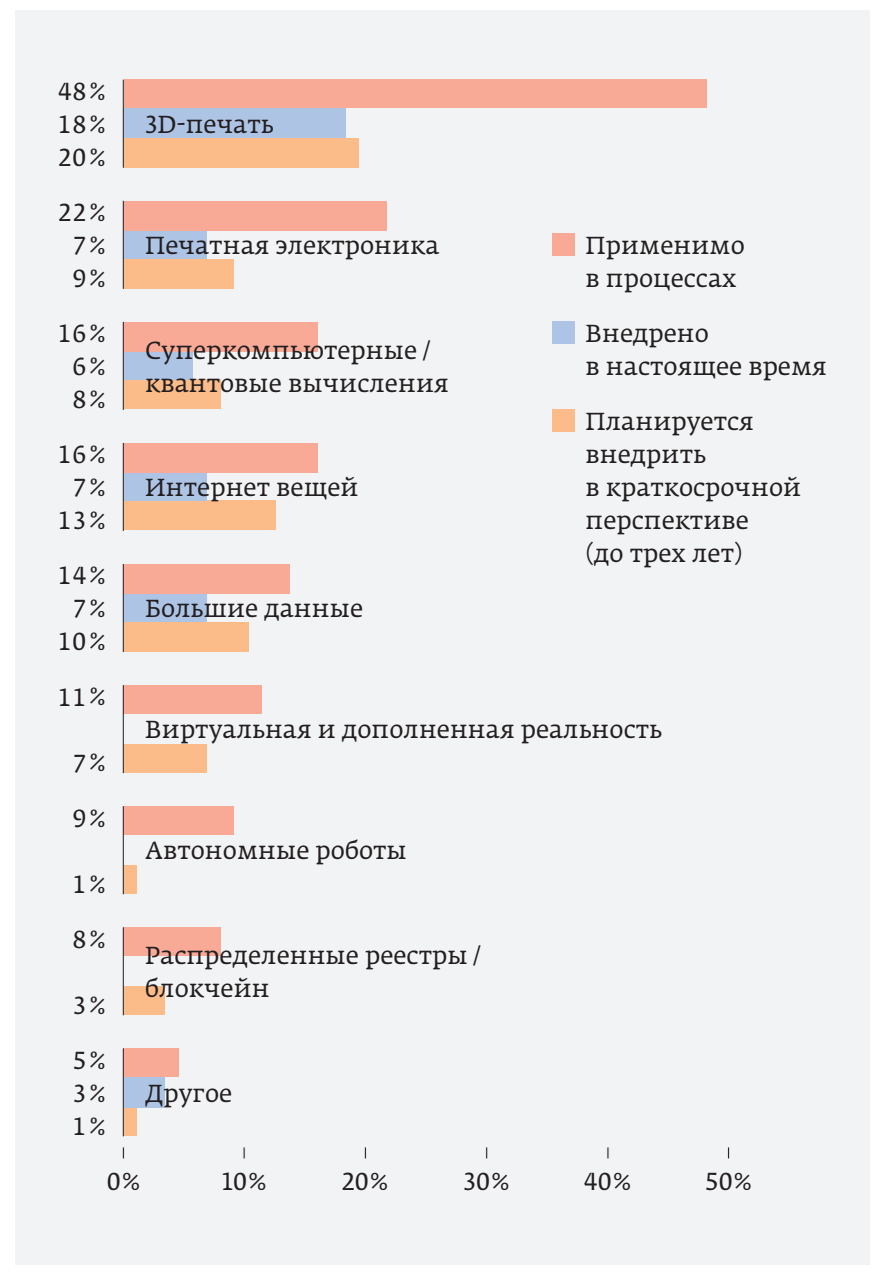

Рис. 1. Оценка технологий "Индустрии 4.0" в радиоэлектронике с точки зрения применимости в процессах, текущего уровня и планов внедрения в краткосрочной перспективе (до трех лет) 


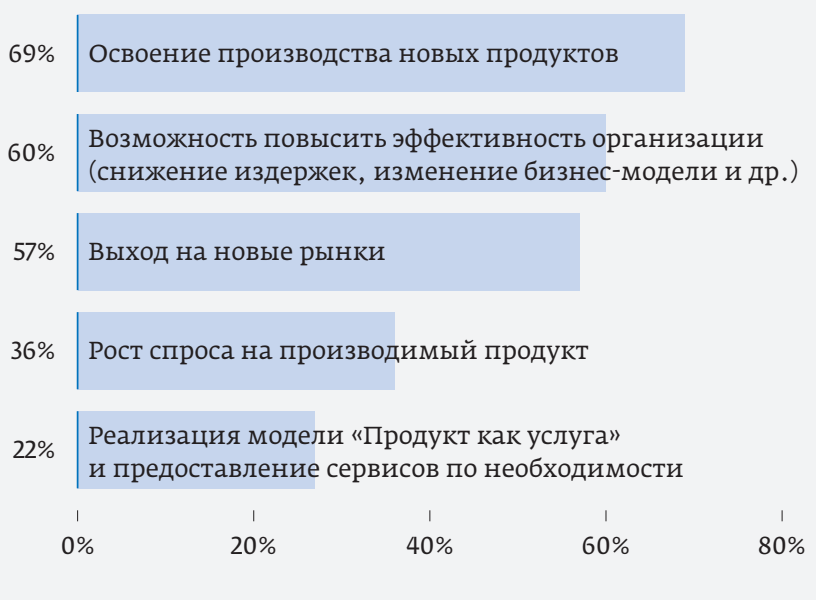

Рис. 2. Оценка организациями возможностей цифровой трансформации радиоэлектронной промышленности

осуществлении договорной деятельности с партнерами или обмене платежными документами с банками).

Автономные роботы могут быть использованы в организациях радиоэлектронной промышленности для автоматизации производственных процессов, рабочих линий, сварочных работ, при этом респонденты отмечают, что внедрение подобных технологий крайне дорогостояще и потому экономически невыгодно. В краткосрочной перспективе лишь 1\% организаций планирует внедрить у себя автоматизированную транспортную систему.

Организации радиоэлектронной промышленности в своей деятельности уже применяют (как минимум на уровне пилотных проектов) технологии больших данных, Интернета вещей, печатной электроники, суперкомпьютерных, квантовых и параллельных вычислений, искусственного интеллекта и готовы развивать указанные направления как в краткосрочной, так и в долгосрочной перспективе.

\section{ОЖИДАНИЯ ОТ ЦИФРОВОЙ ТРАНСФОРМАЦИИ ОТРАСЛИ. БАРЬЕРЫ И ИНСТРУМЕНТЫ СТИМУЛИРОВАНИЯ}

В цифровой трансформации отрасли 69\% организаций российской радиоэлектронной промышленности видят возможность освоения производства новых продуктов, 60\% - возможность повышения эффективности за счет снижения издержек, изменения бизнес-моделей и других факторов, 57\% - выхода на новые рынки, 36\% - роста спроса на производимый продукт и 22\% - возможность реализации модели "продукт как услуга" и предоставление сервисов по необходимости (рис. 2). В качестве потенциальных опасностей респонденты отмечают увеличение конкуренции (49\%) и падение спроса

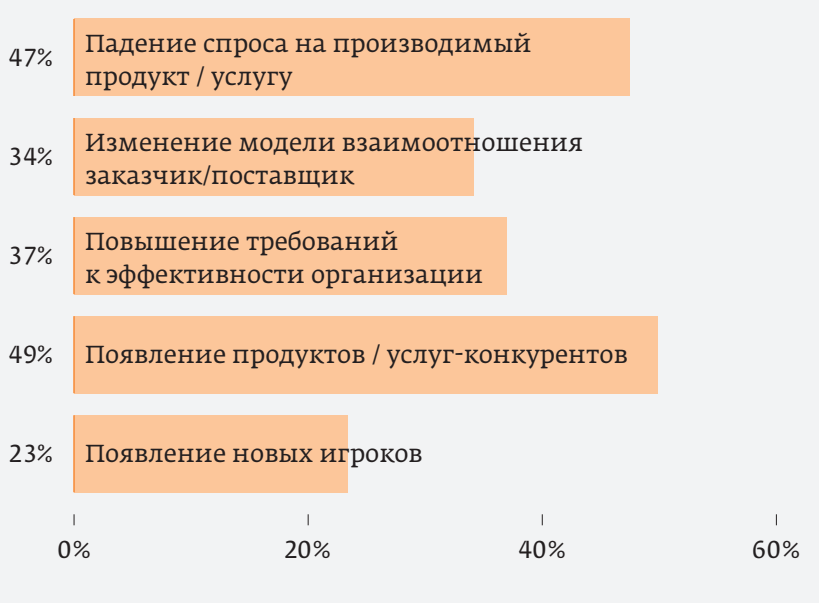

Рис. 3. Оценка организациями опасностей цифровой трансформации радиоэлектронной промышленности

на производимый продукт (47\%), что можно объяснить особенностями развития российской радиоэлектронной промышленности, привыкшей ориентироваться на выполнение государственного оборонного заказа, а не на рыночные тенденции (рис. 3).

По мнению респондентов, основными факторами, оказывающими влияние на процессы цифровой трансформации российской радиоэлектронной промышленности, являются вопросы финансирования, стандартизации и нормативно-методологической базы, подготовки кадров. Проблемы с финансированием препятствуют цифровой трансформации, по мнению 74\% опрошенных организаций, практически такой же процент организаций (75\%) выбрали целевое финансирование в качестве стимула цифровой трансформации. Барьеры, связанные с отсутствием четких стандартов и нормативно-методологической базы, и пользу от наличия стандартов и нормативно-методических документов отметили 46 и 52\% респондентов соответственно. В качестве сдерживающих факторов 36\% организаций выделили отсутствие необходимых цифровых платформ, 33\% - неразвитость инфраструктуры, при этом 41\% респондентов указали, что для развития цифровой трансформации необходимо создание цифровых платформ, экосистем, единых баз данных. В качестве препятствий цифровой трансформации 46\% опрошенных организаций отметили отсутствие квалифицированных кадров, 22\% - отсутствие рыночных стимулов. При этом необходимость сохранения рыночных позиций в качестве стимула цифровой трансформации отметили 29\% опрошенных организаций. Наличие доступной информации о существующих системах автоматизации бизнес-процессов, а также тренинги и мастер-классы по вопросу цифровизации благоприятно отразятся 


\section{Testing\&Control}

27-29 октября 2020 Москва, Крокус Экспо 17-я Международная выставка испытательного и контрольноизмерительного оборудования

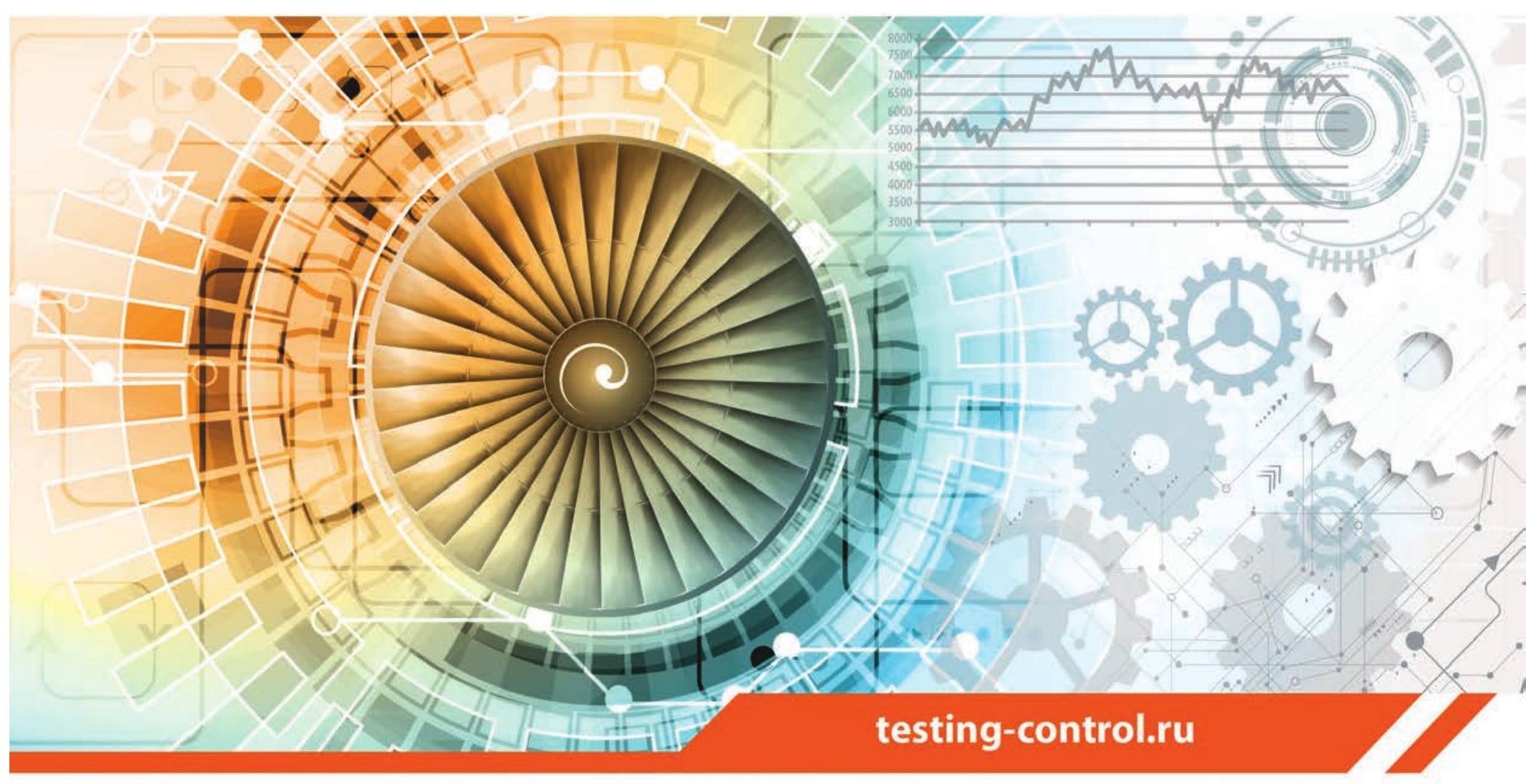

(4)

Измерительное и метрологическое оборудование

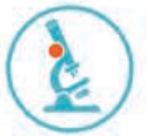
для лабораторного контроля

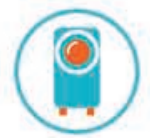

Производственный контроль и машинное зрение

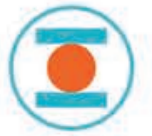

Испытательное оборудование

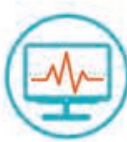

Системы диагностики и мониторинга 
на трансформации, по мнению 38 и 34\% организаций соответственно. Вместе с тем 17\% респондентов сообщили о непонимании того, в чем заключается цифровая трансформация

\section{РОССИЙСКАЯ ЭЛЕКТРОНИКА ДЛЯ ЦИФРОВОЙ ТРАНСФОРМАЦИИ}

Для цифровой трансформации организации радиоэлектронной отрасли готовы предложить отдельные продукты (18\% респондентов) и технологии (7\% респондентов) в области производства СБИС, киберфизических систем, промышленного Интернета вещей, технологии синхронизации времени (в том числе в ДВ-диапазоне), телекоммуникационных, информационных и SMT-технологий (рис. 4). Собственные решения в области разработки и сопровождения программного обеспечения (цифровые платформы, веб-приложения, информационно-аналитические порталы и системы), информационной безопасности, обеспечения каналов спутниковой связи в труднодоступных районах имеют 5\% опрошенных организаций. Кроме того, организации российской радиоэлектронной промышленности развивают собственные решения в области разработки отечественной САПР, спецстойкой ЭКБ, моделей полупроводниковых приборов с возможностью экстракции их SPICE-параметров, систем контроля доступа, SCADA-систем, сервисного обслуживания изделий, изготовления магнитопроводов и гальванических покрытий.

В организациях радиоэлектронной промышленности практически полностью (99\%) автоматизированы процессы бухгалтерского учета. Велика доля автоматизации складских процессов (59\%) и документооборота (54\%). Значительно меньше доля автоматизации управленческого учета (44\%), управления производством (33\%), управления взаимоотношениями с клиентами (30\%) и поставщиками (22\%), логистики (30\%).

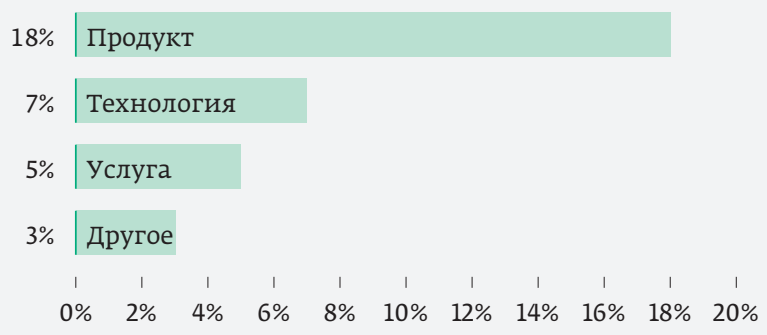

Рис. 4. Оценка уровня готовности организаций радиоэлектронной промышленности развивать собственные решения для цифровой трансформации. Автоматизация бизнес-процессов
Прогнозирование автоматизировано у 14\% респондентов, а отдельные ресурсозатратные процессы роботизированы лишь у 2\% опрошенных организаций (рис. 5).

Основную роль в автоматизации бизнес-процессов в организациях радиоэлектронной промышленности играет продукция 1С: ее доля в системах бухгалтерского учета составляет 90\%, в системах автоматизации складских процессов-70\%, в системах управленческого учета - 63\%, в системах документооборота - 62\%, в системах логистики и прогнозирования - по 58\%, в системах управления взаимоотношениями с поставщиками и с клиентами - 53 и 50\% соответственно. Самая низкая доля продукции 1С (31\%) наблюдается в структуре систем управления производством, где достаточно велика доля собственных разработок организаций радиоэлектронной промышленности (31\%), что может быть обусловлено специфическими особенностями отраслевых производственных процессов.

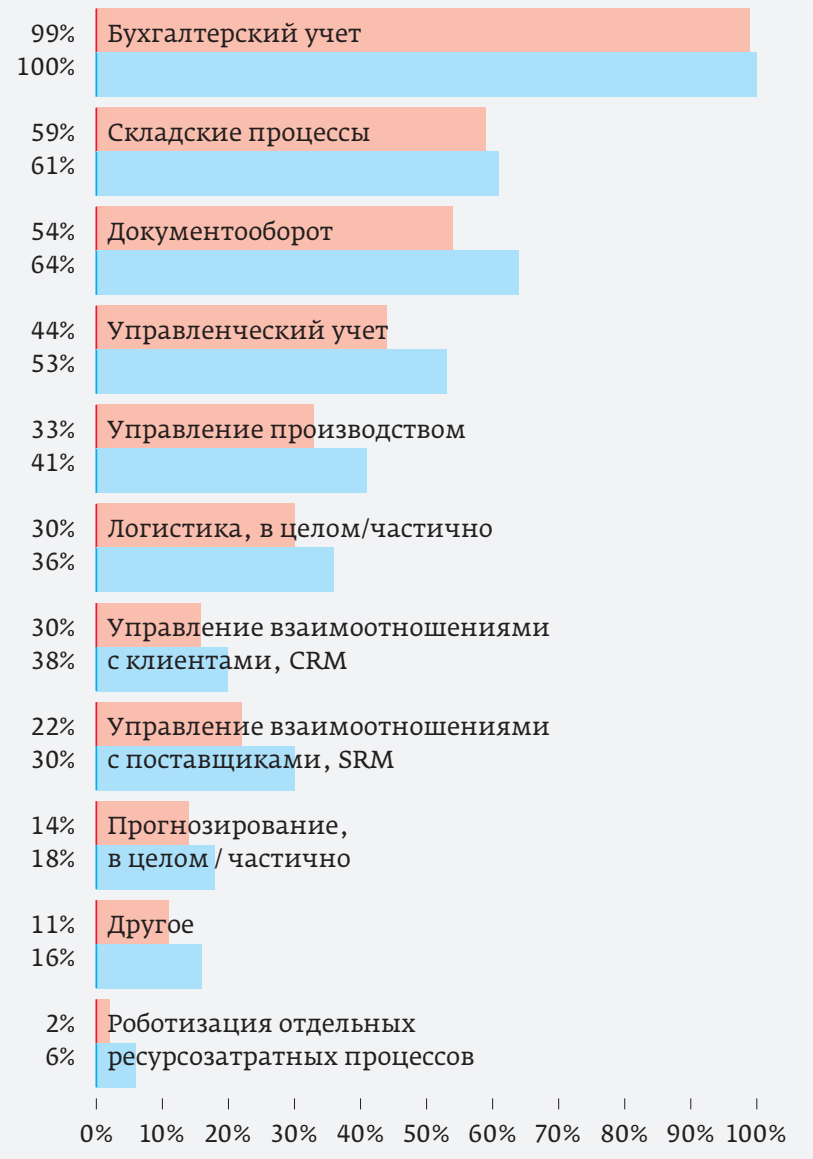

Рис. 5. Текущий и ожидаемый уровень автоматизации бизнес-процессов в радиоэлектронной промышленности 


\section{ИЗДАТЕЛЬСТВО «ТЕХНОСФЕРА» ПРЕДСТАВЛЯЕТ СЕРИЮ КНИГ «МИР РАДИОЭЛЕКТРОНИКИ»}

Уника^ьность этой серии в том, что в реАакционный совет вошАи крупнейшие специалисты в Аанной области, которые в силу своих профессиональных обязанностей хорошо преАстав^ют как направление развития современных технологий, так и их востребованность в нашей стране. Члены реАакционного совета принимают участие и в отборе книг А^я серии, и в научном реАактировании, обеспечивая их высокий уровень. В настоящий момент в серии вышло более 30 книг.

\section{ИзАательство "ТЕХНОСФЕРА॥ СОвМестно с АеПарта- М РИНСРОМТОРГ Ментом РЭП Минпромторга РФ приглашает РУковоАИ- телей И специалистов преАприятий раАиоэлектрон- ной промышленности К Участию в изАании серии иМир раАиоэмектроникиі.}

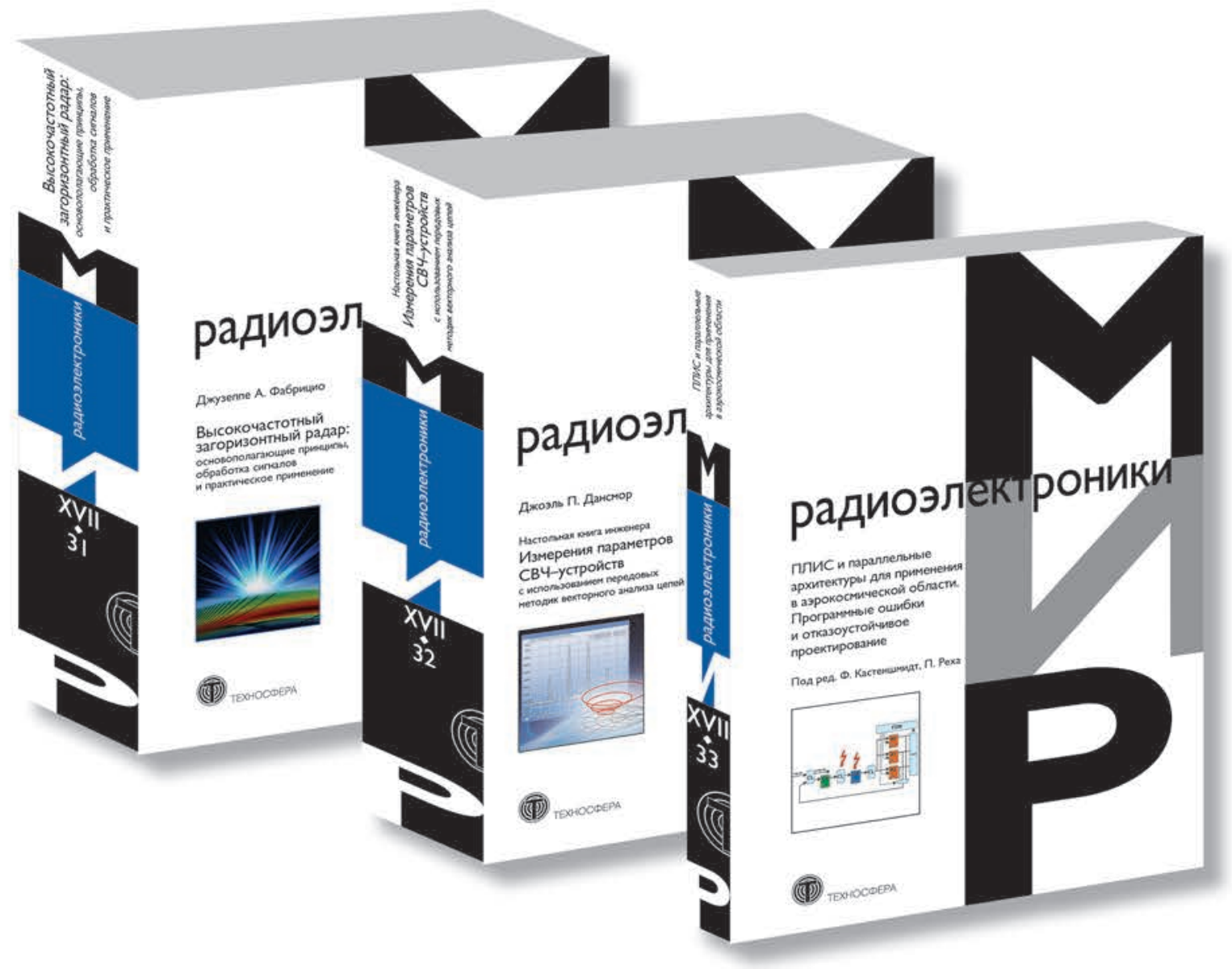

Если у Вас есть желание издать свою книгу или принять участие в научном редактировании переводного издания, направляйте Ваши предложения по адресу redsovet_knigi@electronics.ru

\section{Как заказать наши книги?}


Продукты собственных разработок используются организациями достаточно активно: 23\% респондентов применяют их в системах логистики, 21\% - в системах управления производством, 21\% - в системах управления взаимоотношениями с поставщиками, 19\% - в системах управления взаимоотношениями с клиентами, 17\% - в системах прогнозирования, 13\% - в системах управленческого учета, 12\% - в системах складских процессов, 11\% - для документооборота.

Помимо 1C, организации радиоэлектронной промышленности используют информационную систему "Ресурс», которая применяется для автоматизации управленческого учета, управления взаимоотношениями с поставщиками (SRM) и клиентами (CRM), в системах документооборота (в зависимости от конкретного направления автоматизации к данному продукту прибегают 4-5\% опрошенных организаций). Кроме вышеупомянутых решений, для управления производством 10\% организаций российской радиоэлектронной промышленности применяют систему "Лоцман", 7\% - SCADA; для автоматизации документооборота 4\% организаций используют систему "Дело», 2\% - систему "Лоцман».

В краткосрочной перспективе автоматизация процессов бухгалтерского учета будет доведена до уровня 100\%. Документооборот планируют автоматизировать 10\% опрошенных организаций; управленческий учет 9\% респондентов; управление производством, управление взаимоотношениями с поставщиками (SRM) и клиентами (CRM) - по 8\% организаций; логистику 6\%; прогнозирование - 4\%. Роботизировать ресурсозатратные процессы в краткосрочной перспективе планируют 4\% организаций.

\section{$\therefore *$}

Результаты цифровой трансформации, по мнению респондентов, зависят от трех ключевых факторов - финансирования, стандартизации и нормативно-методологической базы, кадров. Необходимость

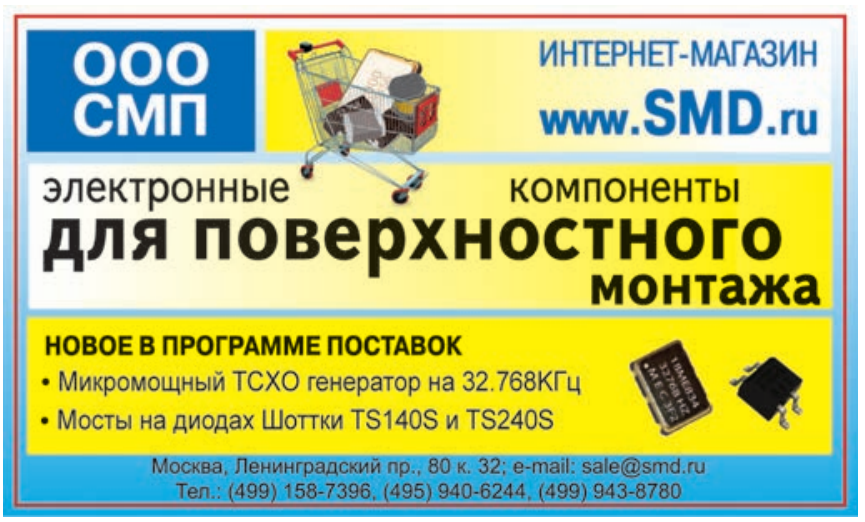

создания соответствующей системы правового регулирования и подготовки высококвалифицированных кадров четко обозначены на государственном уровне в настоящее время в структуре национальной программы «Цифровая экономика» в качестве отдельных федеральных проектов выделены направления "Нормативное регулирование цифровой среды» и «Кадры для цифровой экономики».

Если говорить о проблемах стандартизации, то в этой сфере для нашей страны характерно некоторое отставание от других глобальных игроков: например, как отмечается в программе "Цифровая экономика", в отличие от большинства стран, в России по состоянию на 2016 год не было выработано стандартов оценки центров хранения и обработки данных. Выявленная проблема, безусловно, требует серьезной проработки, при этом запланированные меры по ее решению четко обозначены в дорожной карте программы по направлению "Нормативное регулирование». Системная работа в области стандартизации позволит в перспективе российским организациям занять более выгодные позиции на ранних этапах развития таких сфер, как 5G, где стандарты еще не сформированы.

В ходе проведенного опроса было подтверждено наличие ряда сложностей в сфере подбора кадров в радиоэлектронной промышленности [1]. Другое важное ограничение, препятствующее процессам цифровой трансформации в нашей отрасли, связано с тем, что организации российской радиоэлектронной промышленности пока в значительной мере не могут на равных конкурировать с крупными иностранными игроками даже на внутреннем рынке [2]. Российская радиоэлектронная промышленность все еще находится на переходном этапе к рыночной экономике. Когда большинство организаций отрасли займет рыночные ниши, то сможет проактивно в них действовать. Тем не менее нельзя не отметить положительную тенденцию в сфере конкурентоспособности, что дает надежду, что при развитии системы мер поддержки отечественной продукции на внутреннем рынке российская продукция со временем сможет массово выйти и на мировой уровень.

\section{ЛИТЕРАТУРА}

1. Фомина А. Кадровые проблемы радиоэлектронной отрасли. Результаты социологического опроса // ЭЛЕКТРОНИкА: Наука, Технология, Бизнес. 2017. № 7. С. $108-120$

2. Фомина А. Что сдерживает диверсификацию радиоэлектроники? Результаты исследования потенциала отрасли по наращиванию производства гражданской продукции // ЭЛЕКТРОНИКА: Наука, Технология, Бизнес. 2018. № 4. C. 164-167. 


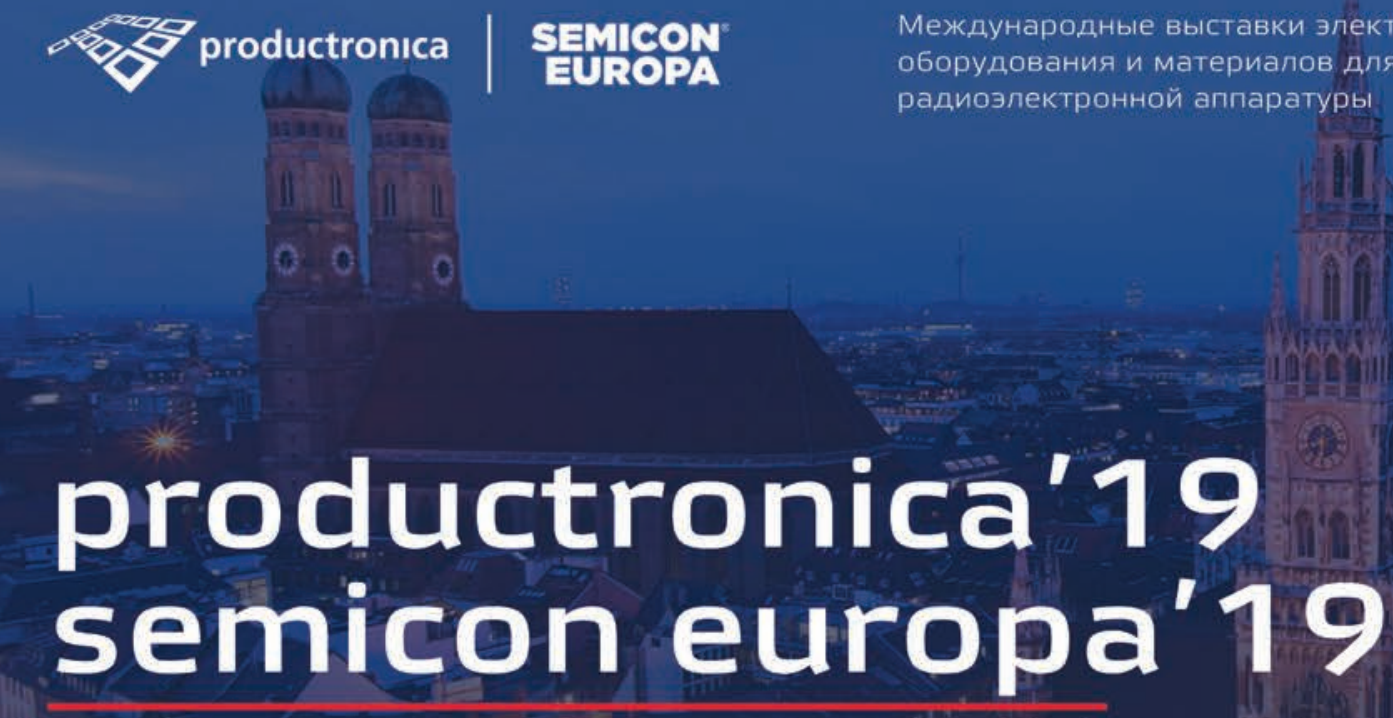

электроники, технологий оборудования и материалов для производства радиоэлектронной аппаратуры

\section{Только вместе с нами самые яркие события!}

11 - 15 ноября

Германия,
Мюнхен
От 850 Евро

на 5 дней*

*цена указана без НДС. Оплата по курсу ЦБ на день оплаты. В стоимость включено: перелет, проживание, экскурсия в политехнический музей, входной билет и русскоязычное сопровождение на выставке, посещение производств, приветственный ужин.

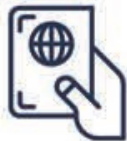

\section{Визовая поддержка}

Мы поможем в формировании

правильного пакета документов,

оформлении приглашения, анкеты и

страховки.

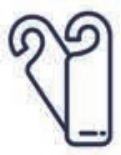

\section{Отели}

Только с нами - выгодные цены на проживание в горячий сезон выставок. Мы бронируем номера за год до мероприятия.

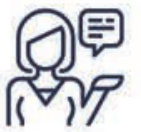

\section{Экскурсии по стендам}

Каждую группу сопровождает гид - наш эксперт в оборудовании и технологиях, который поможет вам преодолеть языковой барьер при общении.

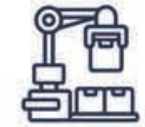

Посещение производств С нами вы посетите известные заводы возможность, которая предоставляется только организованной группе и компании с именем.

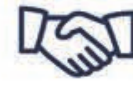

\section{Деловые связи}

Наши групповые бизнес-туры - это уникальная возможность для общения, знакомств и новых деловых контактов.
Подробная информация:

на сайте:

productronica2019.ru

по телефону: +7 495 788-44-44

Заявки принимаются по адресу: productronica@ostec-group.ru 
TEXHOCФEPA РЕКЛАМНО-ИЗДАТЕЛЬСКИЙ ЦЕНТР

\section{0\% ГАРАНТИЯ} ПОЛУЧЕНИЯ ВСЕХ НОМЕРОВ

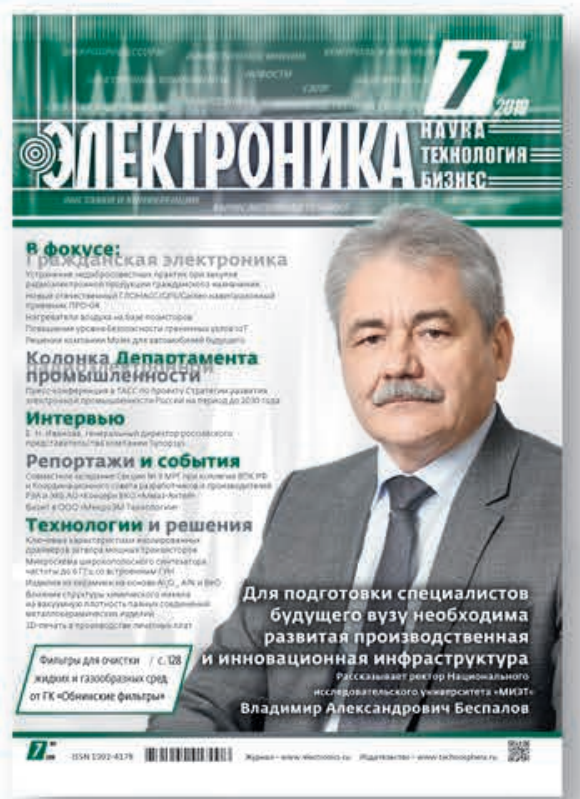

Стоимость 2200 р. за номер

Периодичность: 10 номеров в год www.electronics.ru

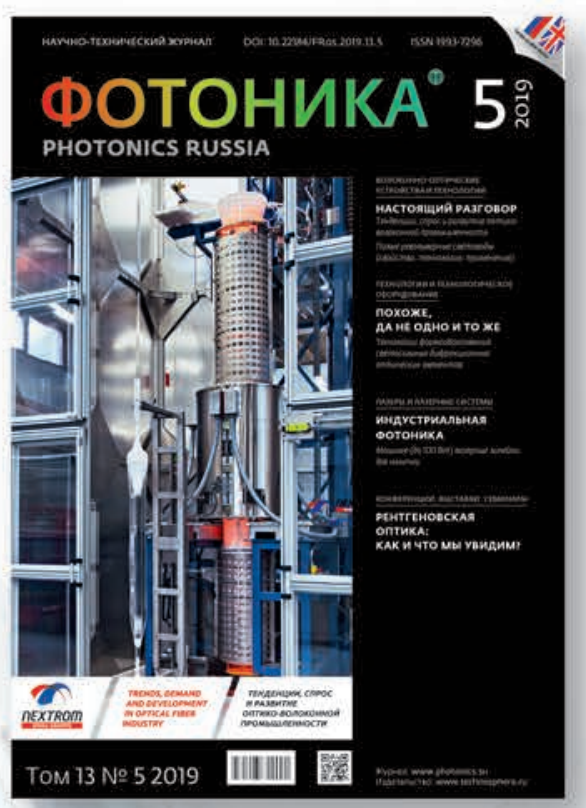

Стоимость 1430 р. за номер

Периодичность: 8 номеров в год www.photonics.su

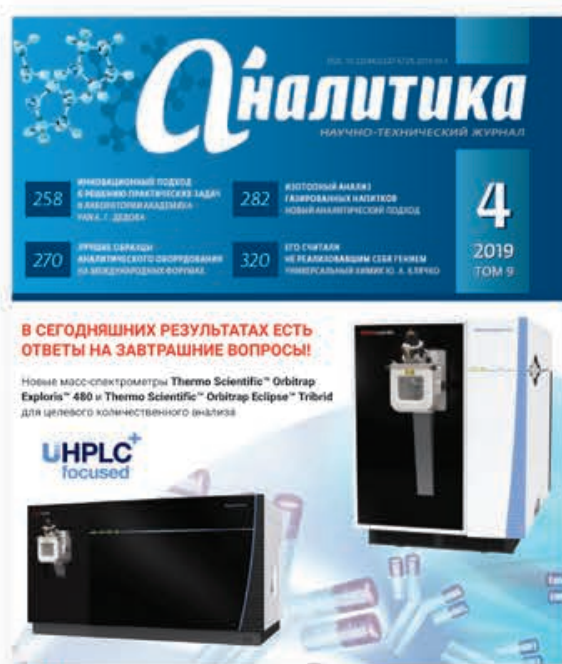

Thermo

IIIмс-аналитика

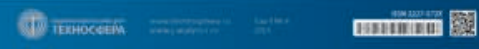

Стоимость 1430 р. за номер

Периодичность: 6 номеров в год www.j-analytics.ru

\section{ПОДПКСКА НА ХУРНАЛЬ}

\section{www.technosphera.ru}

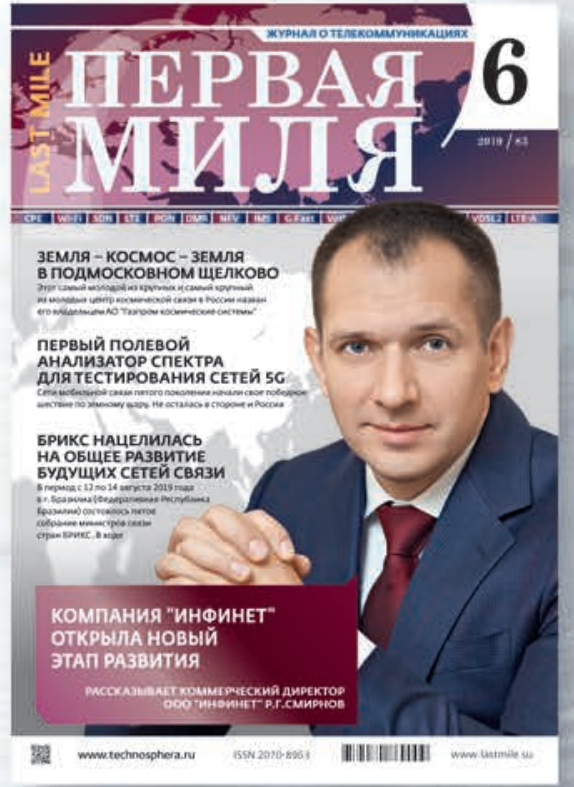

Стоимость 1056 р. за номер

Периодичность: 8 номеров в год www.lastmile.su

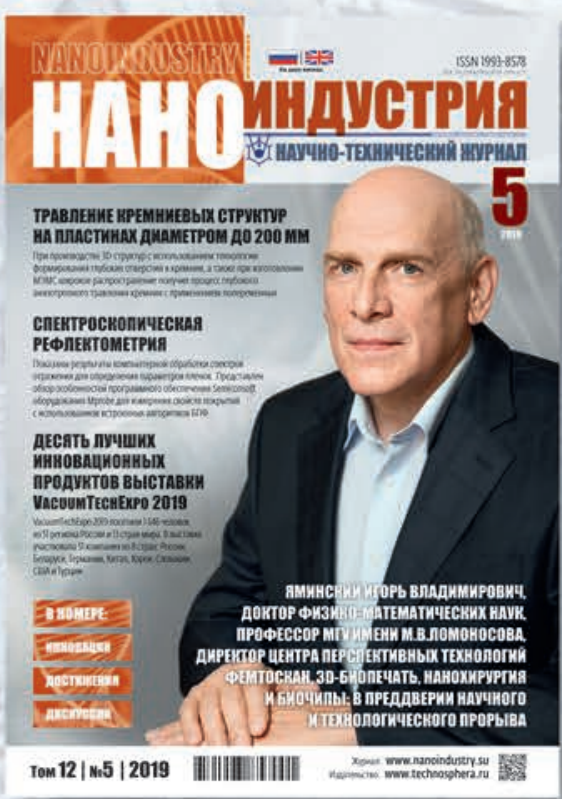

Стоимость 1287 р. за номер

Периодичность: 8 номеров в год www.nanoindustry.su

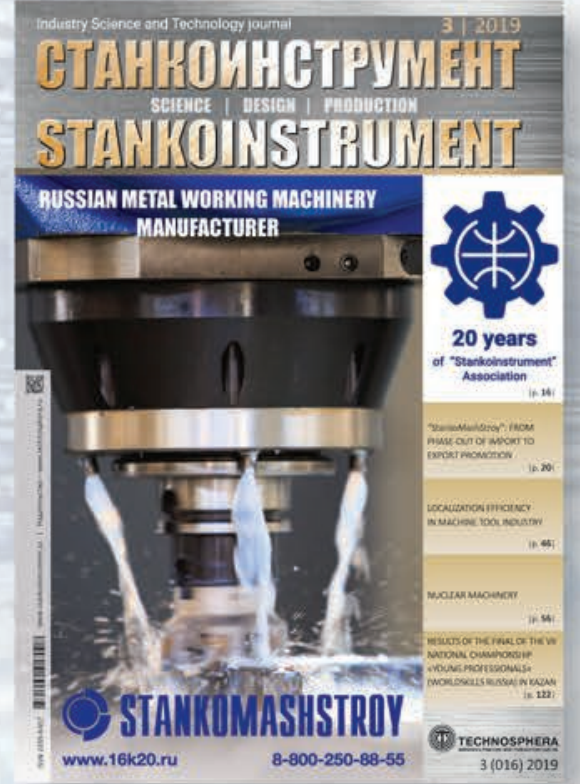

Стоимость 1716 р. за номер

Периодичность: 4 номера в год www.stankoinstrument.su 